\title{
¿VÍCTIMAS PASIVAS?: HIJOS E HIJAS DE MUJERES VÍCTIMAS DE VIOLENCIA DE GÉNERO
}

\author{
¿Passive victims?: sons and daughters of women victims of gender violence \\ ¿Vítimas passivas?: filhas e fillhos de mulheres vítimas de violência de género \\ Rosalía Carrillo Meráz \\ Universidad Autónoma de Tlaxcala, México. Telf.: 5526532086. Correo electrónico: \\ apanerowa@hotmail.com

\section{Graciela Jiménez Bernal} \\ Universidad Autónoma de Tlaxcala, México. Telf.: 2411159536. Correo electrónico: \\ gracejb@hotmail.com
}

\begin{abstract}
Resumen
En México, en la década de 1990 se crean los primeros refugios para mujeres víctimas de violencia con el fin de atenderlas y darles un lugar donde vivir al momento de huir de su agresor. Se diseñaron estrategias para atenderlas de manera integral pero, en un inicio no se pensó en sus hijos e hijas, quienes llegaban con ellas al refugio y sólo se les entretenía mientras psicólogas y trabajadoras sociales atendían a sus madres. Ahora, ante la necesidad de proteger a la comunidad infantil en situación de refugio, empiezan a diseñarse estrategias para dar seguimiento y atención a estos menores que antes eran ignorados como víctimas.

Palabras clave: maltrato infantil, violencia doméstica, refugios.
\end{abstract}

\begin{abstract}
In México, in 1990's it was create the first refuges for women victims of violence in order to attend and give them a place to live when her run away from their agressor. Strategies for attend integrally were designed but, at first there was not thought of their sons and daughters, who came whit her at the refuge and they were ignored until their mom's were attended. Now, is indispensable to protect the child comunity in refuge situation, begin to
\end{abstract}


disign strategies to follow up and care these children who were previously ignored as victims.

Key words: child abuse, domestic violence, refuges.

\section{Resumo}

No México, na década de 1990 os primeiros abrigos para mulheres vícitmas violência, a fim de encontrá-los e dar-lhes um lugar para viver quando seu agressor fugindo criado. estratégias para tratar de forma holística foram projetados, mas não inicialmente pensou em seus filhos e filhas, que vieram com eles para o abrigo e só foram entretidas enquanto psicólogos e assistentes sociais participaram com suas mães. Agora, confrontados com a necessidade de proteger situação dos refugiados comunidade infantil, começam a diseñanse estratégias para monitorar e cuidar destas crianças que anteriormente ignoradas como vítimas.

Palavras chave: abuso infantil, abrigos de violência doméstica.

\section{Introducción}

Cuando hablamos de violencia de género en el ámbito doméstico, debemos reconocer que las mujeres adultas no son las únicas víctimas, también lo son sus hijas e hijos quienes son agredidos de manera directa e indirecta por ambos padres. La exposición a este tipo de violencia tiene un impacto negativo evidente en la vida de los infantes pues vivir en una familia donde la madre es maltratada los obliga a experimentar situaciones de terror, control y tristeza, lo que conlleva al aprendizaje de "modelos" que se basan en el abuso de poder y desigualdad, mismos que pueden ser repetidos cuando éstos alcancen la edad adulta si no son atendidos adecuadamente por sus padres y por las instancias correspondientes en atención y protección de la niñez.

Es necesario y urgente dar visibilidad a niños y niñas que, a pesar de verse inmersos en situaciones de violencia de género grave y extrema, no son considerados como víctimas directas, dificultando así el proceso de intervención y de recuperación. Tal es el caso de los Refugios para Mujeres Víctimas de Violencia, los cuales centran su atención en las madres, tratando a los infantes como un agregado a quien deben entretener mientras la mujer es atendida. 
En la segunda investigación elaborada por Save the Children (Ayllón, 2011) donde el objetivo principal fue conocer y valorar la atención institucional en tres estados europeos de los hijos y las hijas de mujeres víctimas de violencia de género, los resultados evidenciaron que, pese al aumento de concienciación respecto a la situación de estos infantes, todavía existen muchas carencias para poder garantizar plenamente una respuesta adecuada desde la perspectiva de derechos de la infancia. En el caso de las madres, todavía no existe una conciencia plena que visivilice a los hijos como víctimas directas de la violencia que ellas sufren, esto conlleva a una alta probabilidad de que se produzca la repetición de patrones que generan comportamientos violentos, tanto en la etapa de la infancia como en la juventud y en la edad adulta.

Cabe mencionar que muchos de los casos de las madres que acuden a los refugios en busca de ayuda, terminan regresando a su casa y perdonando a su pareja, lo que provoca que los infantes también sean regresados al ambiente familiar donde, seguramente, serán de nuevo víctimas de la violencia.

Aquí la diferencia estriba en que las mujeres pueden defenderse y optar por abandonar o no a su pareja. Los infantes, por el contrario, no tienen capacidad de decisión y deben adecuarse a lo que la madre o el padre decidan por ellos, dejando de lado su opinión o deseos, pues debe ceñirse a lo que los adultos dicten.

\section{Metodología.}

El presente trabajo se llevó a cabo en el refugio para mujeres víctimas de violencia y sus hijas e hijos del estado de Tlaxcala. Se recurrió al método cualitativo utilizando las técnicas de observación participante y la entrevista semi estructurada a través del juego para conocer las experiencias de los infantes que permanecieron en el refugio entre los meses de abril, mayo y junio del 2016.

Se seleccionaron diez infantes: tres niñas y siete niños de entre los dos y once años de edad para ser observados y a los cuales se les hicieron preguntas a través de juegos e interacción con sus compañeros/as para conocer su experiencia de violencia doméstica y sus reacciones ante la misma. Se buscó que el perfil de cada infante fuera diferente para poder comparar sus experiencias, percepciones y reacciones. También se revisaron 
expedientes familiares con el fin de conocer las causas de su estadía en el refugio y su procedencia.

\section{Sobre el maltrato infantil}

Para entender sobre el problema del maltrato infantil debemos tener en cuenta dos premisas: 1) las niñas y niños son entes dotados de derechos que han sido vulnerados por siglos gracias a las creencias culturales y 2) aunque actualmente se lucha por preservar los valores de respeto y tolerancia hacia los infantes, nuestra sociedad presenta un atraso significativo, pues los padres o responsables de crianza, ponen poca atención a las necesidades primordiales de sus hijos e hijas, como es el amor y la comprensión, no respetan su derecho a ser niños y los obligan a adaptarse al imperante mundo de los adultos.

Para explicar el término, según la Organización Mundial de la Salud:

El maltrato infantil se define como los abusos y la desatención de que son objeto los menores de 18 años, e incluye todos los tipos de maltrato físico o psicológico, abuso sexual, desatención, negligencia y explotación comercial o de otro tipo que causen o puedan causar un daño a la salud, desarrollo o dignidad del niño, o poner en peligro su supervivencia, en el contexto de una relación de responsabilidad, confianza o poder. La exposición a la violencia de pareja también se incluye a veces entre las formas de maltrato infantil (OMS, 2003)

Por otra parte, para el Fondo de las Naciones Unidas para la Infancia (UNICEF, por sus siglas en inglés), el maltrato infantil puede ser ejecutado por omisión, supresión o transgresión de los derechos individuales y colectivos, e incluye el abandono completo o parcial en contra del segmento de la población conformado por niños, niñas y jóvenes hasta los 18 años que sufren ocasional o habitualmente actos de violencia física, sexual o emocional, sea en el grupo familiar o en las instituciones sociales. (UNICEF, 2011).

En este sentido, el maltrato infantil refiere todo acto con el fin de dañar, controlar o persuadir al niño o la niña, ya sea por medio de agresiones físicas, psicológicas, sexuales u omisiones de cuidado. Es importante reconocer que en el caso de los niños estudiados en este trabajo, no sólo son víctimas directas de la violencia sino que también, como menciona 
la OMS, son victimizados a través de las exposiciones de violencia vividas entre los padres, ya sea por ser espectadores o por tener que hacerse responsables de sus hermanos (o incluso de la madre), siendo la figura paterna, el principal agresor.

Resulta entonces, un tanto incongruente que los niños se sientan inseguros dentro de su familia, pues esta es la instancia que, por excelencia debería reconocerse como un sitio de confort y protección para los menores, sin embargo, la mayoría de las veces es aquí donde mayormente se da el maltrato infantil.

Al respecto, Manterola reconoce que: "El maltrato a los niños no es un mal de la opulencia ni de la carencia, sino una enfermedad de la sociedad" (Manterola,1992). Sin embargo, contradiciendo la postura de Manterola, en los estudios realizados sobre maltrato infantil, queda evidenciado que este problema sí es un mal de carencia, pues es en los estratos más bajos de la sociedad donde se registran más casos de abuso y violencia haciamenores. Los factores son varios, pero todo indica que a menor oportunidad y capital cultural, mayor el riesgo de la reproducción de la violencia.

Obviamente, el problema del maltrato infantil está directamente ligado con el uso abusivo del poder. Según Loredo, el maltrato infantil se ejerce de un miembro de mayor jerarquía (en el caso que nos compete puede ser la madre o el padre), con el fin de producir daño físico y/o emocional, descuido o trato negligente sobre un miembro de menor jerarquía (los hijos e hijas) de manera intencional, haciendo uso de ese poder que le da estatus mientas el o la menor se encuentra bajo su custodia (Loredo, 1994).

Así pues, según Robaina:

La violencia doméstica, y en particular contra el niño, existe en cualquier sociedad y provoca un grave deterioro del individuo y la familia. Es frecuentemente considerado un asunto privado, donde se exacerban los sufrimientos de la pequeña víctima que debe padecer en silencio. Tiene múltiples formas de expresión, pero todas poco evidentes para quien no piensa en ello. (Robaina, 2001:77)

Por otra parte nos encontramos con que desde antaño, el uso de la violencia en contra de los menores, era ejercido con el fin de educar. De hecho, en el Derecho Romano se otorgaba el Pater famili, que correspondía a los derechos que los padres poseían sobre 
sus hijos, y gracias a él tenían total libertad para venderlos, matarlos, castigarlos o abandonarlos (Robaina, 2001). Y a pesar de que actualmente se han diseñado diversos modelos, protocolos y leyes para prevenir el maltrato infantil, en nuestra sociedad sigue prevaleciendo la agresión física y psicológica como una forma de educación legitimada y aceptada en diversos espacios sociales, sobre todo en los rurales, marginales y urbanomarginales, sin dejar de lado, por supuesto, aquellos estratos sociales medios y altos donde las apariencias no permiten revelar este tipo de abusos, sin embargo, también reconocemos su existencia.

\section{Los refugios para mujeres víctimas de violencia y sus hijas e hijos}

En 1996 fueron inaugurados los primeros dos refugios para mujeres víctimas de violencia en México. Uno de ellos llamado "Mujer contemporánea" y el otro "Alternativas pacíficas". Posteriormente se fueron abriendo más refugios, todos a cargo de organizaciones de la sociedad civil (OSC) y en 1999 se crea la red nacional de refugios (RNR), actualmente hay al menos un refugio para mujeres en situación de violencia en cada estado de la república mexicana.

Estos refugios surgieron ante la necesidad de dar resguardo y atención a las mujeres adultas víctimas de violencia extrema que ponían en riesgo su vida o su integridad física y emocional. Sin embargo, la atención de estos refugios tuvo que vivir variaciones pues la mayoría de la población atendida no eran mujeres adultas sino infantes. La Red Nacional de Refugios A.C. en México, refiere que el 70 por ciento de su población se conforma por infantes menores de 12 años que acompañan a las mujeres (Guillé, 2008).

Ante estas necesidades y con el objetivo de mejorar los servicios de los Refugios, pero también de cambiar la visión social hacia esta problemática, fue imperante no volcar la mirada sólo hacia las mujeres adultas sino también hacia sus hijos e hijas. Uno de los mitos más aceptados alrededor de la violencia familiar, es la idea, de los progenitores principalmente, de que mientras no exista violencia de acción (golpes, gritos, castigos, etc.) hacia sus hijos, estos no serán afectados, no obstante las evidencias revelan lo contrario. Los infantes experimentan el mismo tipo de actos violentos que la madre: insultos, amenazas, humillaciones, desvalorizaciones, intimidación y maltrato físico, golpes, 
perciben el miedo, el terror y la desesperanza. También se ha detectado que pueden ser víctimas de violencia sexual por parte de algún familiar o persona cercana a la familia.

Así, el trabajo con hijas e hijos de mujeres víctimas de violencia de género debe implicar, ante todo, el reconocimiento de éstos como víctimas, creando protocolos y modelos de acción encaminados a su tratamiento, pues hasta ahora, son las madres quienes reciben mayor atención dentro de los refugios.

\section{5. ¿Víctimas pasivas?}

En este trabajo se da testimonio de algunas experiencias observadas en la atención con madres e infantes que se han encontrado en una situación de resguardo en un Refugio para Mujeres Víctimas de Violencia, buscamos compartir con el lector una realidad en la que el reconocimiento de estos infantes como víctimas puede ser no una estigmatización sino el camino hacia una mejor intervención y principio de un cambio social hacia la no violencia y la educación para la paz. Se trata de hacer hincapié y visibilizar a las hijas e hijos de las mujeres víctimas de violencia de género como víctimas directas de la violencia.

Hasta hace muy poco, no se consideraba que los infantes estaban expuestos a la violencia de género en el ámbito doméstico, sólo se les trataba como espectadores de la misma. Sin embargo, son actores y protagonistas que intentan y han intentado hacer o decir algo para protegerse a sí mismos, a su madre o sus hermanos. No olvidemos que la violencia se puede vivir de manera directa o de manera indirecta (siendo testigos de la misma) (Asensi, 2007).

El problema es que el estar inmersos en un ambiente violento, el percibir la violencia ejercida hacia la madre y el ser víctimas directas de la violencia doméstica, los niños y niñas sufren diversos daños, como son: la sintomatología internalizante (depresión, ansiedad, ira, estrés, baja autoestima, miedo, confusión), sintomatología externalizante (huellas de maltrato físico, abuso sexual, agresividad, aislamiento, inexpresividad), alteración del desarrollo (descuido, abandono, desnutrición, retraso cognitivo y/o de aprendizaje), alteraciones en las relaciones sociales (timidez, problemas de comunicación, problemas escolares, agresividad, intolerancia) y, en diversos casos, los y las infantes toman responsabilidades que no les corresponden y, a su corta edad, piensan que son los 
encargados de cuidar a sus hermanos(as) o a su madre y protegerlos del agresor, ya sea el padre biológico o la pareja actual de la madre.

Desafortunadamente, en los refugios para mujeres víctimas de violencia, falta mucho por hacer para atender todos estos factores de maltrato en los hijos e hijas de las mujeres que acuden en busca de ayuda. Esto da como resultado que en el paso de estos niños y niñas por el refugio, no se les brinde la atención, el cuidado y las herramientas necesarias para enfrentar las situaciones de violencia dentro de su hogar. Por ello, es muy difícil que estos infantes puedan ser resilientes ante la situación que están viviendo junto con su madre.

\subsection{Experiencias que dejan huella}

Este artículo toma experiencias de niñas y niños que han transitado por el refugio para mujeres víctimas de violencia del Estado de Tlaxcala, mismos a los que se describe con nombres ficticios para proteger su identidad.

Como mencionado anteriormente, aparte de los daños observados en la sintomatología internalizante, externalizante, las alteraciones en el desarrollo y las relaciones sociales, se encuentran responsabilidades que, de ningún modo debería tener un niño o niña, como lo es el reconocerse como el protector de sus familiares. En este sentido, se les cuestionó a los infantes que acudieron al refugio sobre sus experiencias al tratar de “defender" a su madre o hermanos, las respuestas fueron las siguientes:

- "yo le digo que la deje, agarro un palo y le pego a mi papá” (Jonathan, 9 años)

- “ "me puse a darle de patadas" ( Javier, 6 años)

- "me salí a buscar a la policía” ( Juan Pablo, 11 años)

- “mejor me llevé a mis hermanitos afuera para que no se asustarán” (Raquel , 10 años)

- "vi cómo se la llevaba al cuarto para hacerle cosas, yo le digo a mi mamá que no se deje hacer eso, le digo a mi papá que ya no le haga cosas” ( Angélica 11 años)

- “mejor le traje su cerveza y le puse su tele para que ya se calmara” ( Saúl, 9 años) 
- “cuando mi mamá se desmayó yo le di su masaje para que se despertara, así me enseñó el doctor” (Santiago, 6 años)

Las experiencias de estas niñas y niños describen cómo han reaccionado, con sus limitadas posibilidades, sintiéndose responsables de proteger a los miembros de su familia de un padre que los violenta. Algunos de ellos reaccionaron de manera violenta, golpeando con objetos o pateando a su progenitor, otros, ante el miedo que los embargaba, prefirieron huir y proteger a sus hermanos o intentar calmar a su padre y, en uno de los casos más extremos, Javier tuvo que hacerse cargo de reanimar a su madre quien se desmayó por la golpiza que le propinó su pareja. El caso de Javier es uno de los más preocupantes, pues a su corta edad, ha tenido que acompañar a su madre al médico y ha tenido que aprender a atenderla y cuidarla cuando es víctima de la violencia paterna.

Es importante resaltar que dos de los varones optaron por la violencia como forma de defender a su progenitora, mientras que los niños más grandes, de 10 y 11 años, optaron por respuestas más racionales sin intentar enfrentarse al agresor sino buscando proteger a sus hermanos, recurriendo a las autoridades o aconsejando a su madre y a su padre. En ese mismo tenor, Saúl de 9 años, buscó la forma de tranquilizar a su padre trayéndole una bebida embriagante.

Todas estas vivencias generan daños irreversibles en el desarrollo de los infantes, pues como menciona Asensi (2007), se pueden detectar diferentes factores para reconocerlos: baja autoestima, miedo, preocupación, inseguridades y repercusiones físicas como falta de sueño, incontinencia y depresión.

Así, la gravedad de las repercusiones que tiene la violencia de género sobre las mujeres y sus hijos e hijas exige su visibilización. En México, la violencia contra las mujeres ha sido ya catalogada como un problema social y de salud pública (actualmente existe ya un sistema de asistencia en este ámbito: jurídico, laboral y psicológico; aún inacabado pero ya con una jerarquía importante en las políticas públicas). La infancia expuesta a la violencia de género sigue careciendo de una adecuada regulación que reconozca sus derechos como víctimas directas de dicho fenómeno.

Durante mucho tiempo se ha creído que interviniendo con las mujeres, víctimas directas de las agresiones, se intervenía con los hijos e hijas. La profesionalización de los 
Refugios, en México y bajo el acompañamiento de experiencias internacionales, ha descubierto en el trabajo cotidiano como es que este planteamiento centrado únicamente en las mujeres, visibiliza y deja en un segundo plano las secuelas que presentan los infantes expuestos a violencia de género, así como sus necesidades.

Las niñas y niños que han vivido o están viviendo situaciones de violencia de género manifiestan una variada sintomatología según la edad, el tipo de violencia sufrida y su situación familiar. Así, la "actuación” o "protagonismo" de los infantes cambia según el ciclo de la violencia que estén viviendo (Holden, 2003), pueden estar alternando entre sentimientos de culpa: "Es que como me porto mal, dice mi mamá que hago enojar a mi papá" (Jaime, 8 años) o con episodios de rabia hacia su mamá.

Dentro de los Refugios es cotidiano el trabajo reparador que se tiene que realizar con madres, hijos e hijas para sanar lazos afectivos, recuperar la figura de autoridad de la madre y poner un alto a las agresiones explicitas que los infantes realizan a estas figuras, pues ellos, al ver la falta de autoridad materna, suelen revelarse como una forma de retar o de manifestar su enojo hacia la figura que "debería" protegerlos. Ellos manifestaron frases hacia su madre como:

- "te odio" (Jonathan, 9 años)

- " "ya no te quiero" (Saúl, 9 años)

- “ya no te voy a hacer caso" (Angélica, 11 años)

Otros infantes manifestaron que en varias ocasiones habían sentido el deseo de herir a su madre con objetos. Como es el caso de Antonio, niño de dos años de edad, quien encuentra en el juego de té un chuchillo de juguete que sin dudar, toma y le coloca a su madre en el cuello mientras ejerce fuerza para enterrárselo y ruidos de enojo.

La otra cara del protagonismo de los infantes en el fenómeno de la violencia de género sufrida por sus madres es cuando ellos empatizan con el sufrimiento de su mamá y asumen papeles de protección hacia ella, oponiéndose a la violencia y/o adquiriendo roles que no les corresponden como "jefes o jefas" de familia. Esta situación los lleva a trabajar a edad temprana para colaborar con los gastos del hogar, sienten que no pueden dejar a la madre sola, aunque ello incluya no jugar o no asistir a la escuela. 
Es evidente que no se puede dejar de trabajar con las mujeres víctimas de violencia de género, pues necesitan espacios de recuperación no sólo como mujeres, sino también como madres. Cuando una mujer toma la decisión de separarse de su agresor y además asume llevarse a sus hijos y/o hijas, automáticamente su organización familiar cambia (familia monomarental), la vulnerabilidad de riesgo y de exclusión social aumenta considerablemente no solo para ella sino también para los infantes y hay que facilitarles la recuperación de las secuelas en los distintos ámbitos que se afectan: familiar, escolar y social.

Dentro de los Refugios, esta línea de recuperación está asumida y se echan a andar medidas y acciones que contribuyen para brindarles espacios terapéuticos familiares e individuales, orientación de las medidas legales que se vayan ejecutando o se ejecutarán en cada caso y la incorporación lo antes posible a la vida escolar. Reconociendo que es en el campo legislativo donde sigue imperando la decisión de los adultos y donde menos se visibiliza a los infantes como víctimas directas.

Por otro lado, los infantes también son víctimas de sus propias madres quienes, al perder la energía y el ánimo para atender las necesidades básicas de sus hijos e hijas se traducen en negligencias y abandonos, siendo altamente culpabilizadas. Además de que utilizan a sus hijos para castigar a su pareja, alienándolos y, en ocasiones, descargando su ira contra ellos, golpeándoles o culpabilizándolos de las actitudes violentas ejercidas por la figura paterna.

Las situaciones anteriores terminan siendo vivencias traumáticas, dolorosas y estresantes que afectan significativamente el desarrollo de cada infante. A la llegada de niños y niñas al Refugio, observamos cómo estas "actuaciones" parecen haber agotado los recursos naturales de los infantes alejándolos de sus capacidades resilientes, dando el mensaje a sus madres y a ellos mismos de que no hay más remedio que vivir así. Los infantes se muestran perturbados en su vida afectiva, cognitiva, conductual y relacional: infringen violencia grave y reiterativa hacia sus pares, amenazan, insultan, rompen, lloriquean, destruyen, muerden, se aislan, irrumpen, padecen lesiones y accidentes que conmocionan la vida de sus próximos y la, ya compleja, vida de sus madres. 
La intervención con infantes realizada en los Refugios ha empezado a dar prioridad a reforzar y reparar el rol materno para así empoderar a la mujer a través de pautas educativas y co educativas con sus hijos e hijas. No obstante lo anterior, el desafío de las familias y de todo Refugio es que el agresor no deja de ejercer violencia tras la separación; la violencia psicológica continúa y se mantiene indefinidamente, esto lo intuyen o lo saben los infantes y es otra fuente de malestar emocional que viven directamente.

Beblee y Sullivan (2007) encontraron que un $88 \%$ de las mujeres víctimas de violencia informaron que los padres y/o padrastros de sus hijos habían hecho uso de ellos (durante la relación y tras la separación) con las siguientes intenciones: seguir en las vidas de las mujeres (70\%), intimidarlas o acosarlas (58\%), obtener información sobre ellas (69\%), fomentar actitudes de oposición hacia la madre (47\%), convencer a la mamá de regresar con el agresor (54\%) y utilizar a los niños y niñas para atemorizarlas (44\%) ejerciendo con ello otro tipo de maltrato secundario hacia los niños: la parentalización. Aquí un llamado puntual a las autoridades que continúan concediendo de facto el derecho al padre agresor a convivir con sus hijos e hijas. Gracias a esto, el interés superior de niñas y niños queda sólo en la teoría.

Partiendo así de la importancia de visivilizar a los hijos e hijas de mujeres víctimas de violencia como víctimas directas, la tarea institucional es evaluar el impacto de esta victimización de acuerdo a diferentes factores como lo son : características personales de los niños y niñas: edad, desarrollo, vulnerabilidad, enfermedades, presencia de disociaciones, circunstancias del maltrato (periodicidad, tipo, gravedad), factores de resiliencia en la figura materna y en las redes de apoyo familiares y sociales.

Existen muchas situaciones adversas durante el embarazo (abortos, bajo peso del bebé, muerte fetal, malformaciones) que pueden ser atribuidas a la violencia de género. Las madres refugiadas comentan que a pesar de que los embarazos de sus hijos les han representado ánimo, ilusión y esperanza, terminan siendo rechazados o vividos como experiencias adversas por los niveles de estrés ante la violencia de pareja vivida. Las insatisfacciones y expectativas ante los bebés se traduce en malos cuidados o descuidos extremos: niños con antecedentes de quemaduras o fracturas graves forman parte de las estadísticas de niños en Refugio. 
Dentro de Refugio, como parte de la atención integral a la infancia, es la canalización a servicios especializados. La canalización a los servicios de neurología y psiquiatría son frecuentes por la presencia de Trastorno por Déficit de Atención (TDAH), Trastorno Oposicionista Desafiante (TOD), Trastornos de Ansiedad y fobias. Estos niños difícilmente logran conciliar el sueño y cuando lo hacen, presentan conductas de terrores nocturnos y/o sonambulismo, trastornos disociativos, conductas autodestructivas y trastornos de la reflexión ética que los deja fuera de las escuelas y atados a la medicación.

\section{2 ¿Qué pasa con la relación madre violentada-hijo?}

En situaciones de violencia de género se dan acontecimientos que no facilitan el apego sano y seguro. Si las bases de los apegos asertivos en las personas no se desarrollan, es indudable que ello repercutirá en los distintos ámbitos como lo es la escuela, la familia, comunidad, relaciones de pareja, trabajo, etc.

En la observación de los bebés que acompañan a las mujeres en una experiencia de Refugio, la presencia de los vínculos es ambivalente. Por un lado, se puede detectar un fuerte apego en los bebés, ya que no pueden perder de vista a su madre y, por otro lado, cuando están con ella lloran de manera inconsolable, muestran angustia e inquietud al grado de somatizar y enfermarse. La madre les representa así, una fuente de tranquilidad pero también una fuente de miedo y angustia. En términos psicológicos estos "dobles" mensajes no dejan de remitirnos a historias y síntomas de esquizofrenia.

Por otra parte, y como ya hemos mencionado anteriormente, las niñas y niños externaron que sienten enojo hacia su madre porque permite que ejerzan violencia en su contra, porque no se defiende y porque no representa una figura de apoyo y protección.

Es importante mencionar que dentro de los refugios se trabaja el apego entre madres e hijos, pero si se continua con un modelo donde la prioridad es la madre y donde los infantes son tomados en cuenta como una extensión de la mujer, estaremos aportando para una doble victimización de los niños pues, por un lado vienen lastimados por las experiencias violentas vividas en su hogar y, por el otro, son ignorados como víctimas al ingresar al refugio donde deberían tener la oportunidad de externar y superar su miedo hacia las figuras materno-paterna y tratar de sanar las heridas provocadas por las 
experiencias previas, logrando no solo empoderarles sino también haciéndoles comprender la situación que viven sus progenitoras, logrando estrechar la relación madre-hijo.

\section{Las alternativas ante la victimización por género}

Una de las alternativas viables en la atención hacia niñas y niños víctimas de violencia y en situación de refugio, son las acciones de co-educación que buscan abandonar los roles estereotipados de lo masculino y lo femenino, pues la transmisión de los roles de género a través de la socialización perpetúa y hace más complicado el cambio de visión que los niños tienen sobre el uso de la violencia y la incapacidad para adquirir nuevos esquemas de actuación y de relación con los otros. Esta interiorización del rol de género "tradicional" fue mostrada por Jaime, de 8 años, quien lloraba aterrado en un rincón pues minutos antes se le había solicitado tomar asiento en la única silla que quedaba libre y que era de color rosa: "Yo no soy niña, no puedo sentarme allí, eso no quiero".

Los niños adoptan roles masculinizados basados en la agresividad, en el abuso de poder, basándose en la violencia por el aprendizaje que han recibido en casa y en su medio inmediato. Las niñas adoptan modelos feminizados basados en la sumisión, dependencia, en la resignación a estar siempre en un segundo plano de importancia. Niñas que ingresan a Refugio, acompañando a su madre, presentan mayormente, siluetas esqueléticas (sin escapar de cuadros de anemia) a diferencia de los varones que mantienen un peso promedio a su edad.

Las madres argumentan que sus hijas "siempre" han comido menos. Es común observar a la hora de la toma de alimentos cómo los hijos varones quitan la comida a sus hermanas sin ninguna intervención asertiva por parte de sus madres.

Las niñas, como condicionante de su género, están presentando conductas antisociales no violentas como el decir constantemente mentiras o de autoagresión: cortarse el cabello, hacerse cortada superficiales en brazos y piernas, dejar de comer, siestas por días completos, manías (comer papel, piedras, lacerarse, etc.), y una excesiva inhibición.

A todo lo anterior, es necesario destacar los sentimientos de desesperanza que los niños empiezan a adoptar tras los graves y reiterativos episodios de violencia en sus hogares de origen. Jonathan, niño de 9 años de edad, rezaba todos los días en voz alta 
después de tomar sus alimentos: "Gracias Dios por los alimentos que mes has dado, aún sin merecerlos", al referirle que era un derecho inherente a su condición humana, él contestaba que no era así, porque se había portado mal.

También, muchos infantes expresan que no tienen esperanza de un futuro mejor, como es el caso de Ana, de 10 años de edad, quien externó: "Yo sé que ya no podré estudiar, no sé porque, pero yo creo que ya no podré ir a la escuela,... no sé porque pero es algo que siento aquí en mi panza”.

Cuando un niño o niña se desarrolla en un hogar donde su padre o el compañero de su madre es violento contra la mujer o hacia cualquier miembro de la familia, aprenden que las personas que supuestamente han de protegerles y cuidarles les agreden, por lo que “interiorizan el binomio amor-violencia como algo natural, integrando la violencia como una actuación válida ante determinadas situaciones, justificable y generalizable a otros espacios y personas" (Horno, 2005: 32). Estos niños y niñas aprenden que es legítimo hacer uso de la violencia para resolver conflictos, pero no por ello se debe de dejar de lado que también pueden desarrollar factores de resiliencia que les permitan adoptar modelos basados en la resolución de conflictos y en el uso de la no - violencia.

En los Refugios, se apuesta por el juego, la música, el buen humor y la necesidad de relacionarse con sus iguales como situaciones propias de la infancia: se crean espacios que motiven el despertar de los sentidos y sentimientos de las niñas y niños. El juego no sólo les contribuye a la re significación y resolución de emociones sino que brinda a los profesionistas la oportunidad de identificar aquellas representaciones simbólicas de cada infante, las creencias que tienen acerca de lo ocurrido, sus percepciones y estilos de afrontar su realidad.

Como menciona una psicóloga encargada de la atención a los infantes: "No hay niño o niña que no recupere la tranquilidad y la sonrisa tras las sesiones de juego y sueño tranquilo y tras un trabajo de ayuda y acompañamiento, el reto es que ello sea sostenido más allá de estos muros".

Lo ideal es que niñas y niños se alejen lo más posible o abandonen los roles de cuidadores- cuidadoras y/o confidentes de sus madres dejando de asumir conceptos y 
responsabilidades que no les corresponden. El objetivo es devolverles los aspectos importantes de su infancia y que la madre comprenda que es su legítimo derecho.

Esto, con el fin de evitar la adultización de los niños como Andrés de 8 años de edad, quien enfático sostenía: "Yo no quiero que me mandes a la escuela - dirigiéndose a la trabajadora social-, quiero que me busques un trabajo para comprarle su casa a mi mamá, ni me mandes a la escuela porque no voy a hacer nada”.

\section{Conclusiones}

Pareciera trillado, pero en la mayoría de las campañas políticas y educativas, se hace énfasis en que "los niños y niñas son el futuro de México". Esto, por supuesto, forma parte de un discurso al que falta todavía mucha acción. Reconocemos que los niños y niñas víctimas de violencia representan una infancia dañada, son una comunidad que requiere atención inmediata para garantizar el respeto a sus derechos humanos.

Requerimos modelos de intervención que brinden atención psicológica tanto a hijos como a sus padres. Hay que resaltar que los niños y niñas no dependen de los programas, dependen de los adultos, por ello, éstos últimos son los responsables de salvaguardar su vida y su salud física, mental y emocional.

Debemos atender a los infantes como víctimas, no con el fin de etiquetarlos sino de tomarlos en cuenta para atender sus necesidades básicas y de protección, y así brindarles un apoyo integral que incluya, entre muchos otros aspectos, el desarrollo de la resiliencia junto con sus madres.

Los niños y niñas deben reconocerse como víctimas para, partiendo de ahí, se inicie un proceso de atención que les permita enfrentar su realidad y aceptar sus duelos, en este caso la separación de sus padres, el alejamiento de su hogar, enfermedades o incluso la muerte. Debe manejarse información limitada, ya que hay aspectos de la vida adulta (violenta) que ellos no pueden entender por su corta edad. Reconocemos que no es posible dar más información de la que pueda asumir, en muchas ocasiones creemos que como han presenciado la violencia se les puede informar de situaciones relativas a las acciones legales, a los chantajes o amenazas serias, pero no es así. Si se les comunican situaciones desagradables, se debe dosificar la información para no saturar a los infantes y no 
“desbordarlos" emocionalmente. Dentro del Refugio, es reconocible cómo los niños y niñas, al irles informando de situaciones desagradables ponen sus límites de tolerancia y/o resolución refiriendo que no desean hablar de ello por el momento o cambian de tema, indicadores que ayudan a regular cada intervención con ellos.

Visibilizar el sufrimiento, los discursos, pensamientos y sintomatologías de los hijos e hijas de mujeres víctimas de violencia implica el inicio de una preparación para tener una mirada de respeto y actitud de contención del daño que sufren. El escucharlos y evidenciar sus vivencias y testimonios no debe representar una afrenta a su intimidad, por el contrario, significa encontrar caminos más precisos de resarcir un poco el daño sufrido.

Si logramos atender a estos niños a temprana edad, lograremos evitar los costos sociales que tendría el ignorarlos, por ello, hacemos un llamado a las autoridades locales, municipales, estatales y federales, para que extiendan su apoyo a los refugios de mujeres víctimas de violencia y sus hijas e hijos, pues estas instituciones funcionan mayormente con apoyos del sector privado y requieren recursos para realizar su trabajo en óptimas condiciones y así poder ayudar al mayor número de mujeres víctimas de violencia y a sus hijas e hijos quienes, como hemos mencionado, son recibidos pero requieren mayores atenciones para lograr un proceso resiliente en sus vidas.

\section{Referencias bibliográficas}

Asesnsi, L.F. (2007, 16 de enero) Violencia de género: consecuencias en los hijos, en Revista Psicología científica 9 (4). Consultada el 22 de enero 2017. http://www.psicologiacientifica.com/violencia-familiar

Ayllon, E (2011) Save The Children. Informe. En la Violencia de Género no hay una sola víctima. Consultado $27 \quad$ de 2016. https://www.savethechildren.es/sites/default/files/imce/docs/violencia_de_genero_v ictima.pdf

Beeble, M.L., Bybee, D. y Sullivan, C.M. (2007). Abusive Men's Use of Children to Control Their Partners and Ex-Partners. European Psychologist, 54-61. (Traducción) 
Guillé Margarita, (2008) discurso de inauguración de la reunión, “Atención Integral a los hijos e hijas de las Mujeres que se encuentran en un Refugio”, INMUJERES, Hotel Radisson Pedregal, Marzo 28, México.

Holden, G.W. (2003). "Children Exposed to Domestic Violence and Child Abuse: Terminology and Taxonomy. Clinical Child and Family”. Psychology Review, 151160.(Traducción).

Horno, P. (2005). Amor, poder y violencia. Un análisis comparativo de los patrones de castigo físico y humillante, Save The Children, Madrid.

Lagarde, Marcela (2012) ¿Cómo se construye la identidad de género?, consultado el 22 de octubre de 2016. www.mujeresparalasalud.org/spip.php?article54

Lamas Martha (2000) El Género. La construcción cultural de la diferencia sexual (Compendio), Universidad Nacional Autónoma de México- Programa Universitario de Estudios de Género, México: Porrúa.

Loredo, A. (1994). Maltrato al menor. México: McGraw-Hill.

Manterola MA. La prevención del maltrato a los menores en México. En: El Maltrato a los niños y sus repercusiones educativas. Memorias del 2do. Simposio Interdisciplinario e Internacional. México, D.F.: Federación Iberoamericana contra el Maltrato Infantil,1992; I:173-184

Organización Mundial de la Salud OMS (2003) Informe mundial sobre violencia y salud, Washington, D.C. OPS

Robaina Suárez, G (2001) El maltrato infantil en Revista Cubana de Medicina General Integral, 17 (1), 74-80

UNICEF (Fondo de las Naciones Unidas para la Infancia) (2011) Estudio sobre el maltrato infantil en el ámbito familiar de Paraguay, Consultado el 18 de diciembre de 2016 https://www.unicef.org/paraguay/spanish/py_resources_estudio_maltrato.pdf 